\section{$\underset{\substack{\text { hommes } \\ \text { \& migrations }}}{ }$}

\section{Hommes \& migrations}

Revue française de référence sur les dynamiques

migratoires

$1277 \mid 2009$

France - Allemagne

\title{
Quand une mémoire familiale devient patrimoine national
}

Fabrice Grognet

\section{(2) OpenEdition}

\section{Journals}

Édition électronique

URL : http://journals.openedition.org/hommesmigrations/179

DOI : 10.4000/hommesmigrations. 179

ISSN : 2262-3353

Éditeur

Musée national de l'histoire de l'immigration

Édition imprimée

Date de publication : 1 janvier 2009

Pagination : 116-120

ISSN : 1142-852X

\section{Référence électronique}

Fabrice Grognet, «Quand une mémoire familiale devient patrimoine national », Hommes \& migrations [En ligne], 1277 | 2009, mis en ligne le 29 mai 2013, consulté le 22 septembre 2020. URL : http:// journals.openedition.org/hommesmigrations/179; DOI : https://doi.org/10.4000/hommesmigrations. 179

Ce document a été généré automatiquement le 22 septembre 2020

Tous droits réservés 


\title{
Quand une mémoire familiale devient patrimoine national
}

\author{
Fabrice Grognet
}

1 Le 30 septembre 2008, avant même sa première visite à la Cité nationale de l'histoire de l'immigration, Marie-Louise Savoy adresse la proposition suivante au musée :

"Je suis d'origine italienne, mon père est venu en France en 1925 avec un contrat de travail, ma mère pour l'épouser au consulat de Saint-Étienne en 1928. Ils sont originaires tous les deux d'un petit village du Trentin : Camposilvano di Vallarsa. J'ai retrouvé leur première carte d'identité française après leur naturalisation.

Pensez-vous que cela puisse faire l'objet d'un don ?"

2 La redécouverte de ces cartes d'identités dans les papiers familiaux remonte en fait à 1998, au moment où Laure, la fille de Marie-Louise, réalise une étude sur les Italiens de Saint-Étienne : “Ma seconde fille, alors étudiante à l'IEP de Grenoble, a fait un mémoire sur le thème La communauté italienne de Saint-Étienne, 1890-1990: un Italien chasse l'autre, de l'intégration à la désintégration à l'Italienne. Il traite des différentes immigrations italiennes qui se sont succédé à Saint-Étienne. Ma fille consacre notamment un chapitre à "Saint-Étienne di Vallarsa, la micro communauté trentine".

Pour cette étude, elle a exhumé les documents que j'avais retrouvés chez ma mère au moment de son décès. Parmi eux, ces premières cartes d'identité française que ma mère avait conservées. Elles m'ont paru être le symbole de cette volonté de mes parents de s'intégrer par le travail, ainsi que l'aboutissement de leurs efforts pour être acceptés et en même temps leur fierté d'être Français." C'est donc au cours de ce travail universitaire que les papiers périmés d'Ettore et Giuseppina se transforment en documents d'histoire, la famille renouant ainsi avec son héritage et sa propre mémoire.

\section{Depuis le Trentin jusqu'à Saint-Étienne}

4 C'est à Camposilvano di Vallarsa que naissent Ettore Pozzera ${ }^{1}$ (1903-1962) et Giuseppina Forti (1906-1989). Village italophone d'une vallée des petites Dolomites, il est situé dans la province alors autrichienne du Trentin (WelschTirol), à proximité de la frontière 
italienne. Au début du $\mathrm{XX}^{\mathrm{e}}$ siècle, la pénurie de travail incite les villageois à partir travailler en Autriche. Avec la Première Guerre mondiale, tous les habitants du village sont déplacés en Italie, vers Bevilaqua ${ }^{2}$, puis en Ligurie. Mais après le traité de SaintGermain-en-Laye (1919) réglant l'issue du conflit, le Trentin devient italien et la frontière autrichienne se ferme.

5 Aîné d'une famille de quatre enfants ${ }^{3}$ et à la recherche d'un emploi, Ettore, comme d'autres hommes de son village, répond alors à une annonce affichée en mairie pour venir travailler en France ${ }^{4}$, le manque de main d'œuvre affectant tout particulièrement le secteur du bâtiment et des travaux publics ${ }^{5}$. C'est ainsi qu'Ettore et son frère cadet, Virgilio, arrivent à Saint-Étienne en 1925, avec un contrat de travail de maçon.

Près de trois ans plus tard, Giuseppina rejoint Ettore. Ils se marient le 18 février 1928 au consulat italien de Saint-Étienne, ville où ils passeront toute leur vie :

"Mon père a toujours été estimé par sa volonté de travail bien fait. Ma mère a travaillé très peu, elle se consacrait aux travaux domestiques et à l'éducation des enfants. Au début de leur mariage, ils ont habité sous les toits, puis ils ont déménagé dans une pièce donnant sur une cour d'immeuble où il y avait d'autres immigrés d'origine arménienne. De cette période, je ne sais à vrai dire pas grandchose, si ce n'est que les premières années n'ont pas été faciles. Ils ont appris le français par eux-mêmes, mon père grâce à son travail, ma mère grâce à des voisines françaises, mais surtout à la suite de la scolarisation de mes frères."

\section{Entre “ici” et "là-bas", l'adoption de la France}

7 Le 25 avril 1929 naît Elvio, bientôt rejoint le 7 septembre 1931 par Maurice. Avec l'arrivée des enfants, la famille s'établit dans un autre appartement de deux pièces, toujours dans le même immeuble, où Ettore et Giuseppina hébergent temporairement les membres de leurs familles respectives cherchant du travail en France :

"Après leur mariage, mes parents ont accueilli successivement, dans leur petit appartement de deux pièces, des cousins de mon père, les frères de ma mère, lorsque ces derniers sont venus à leur tour travailler à Saint-Étienne. Mon grandpère paternel est aussi venu, pour des contrats temporaires, toujours hébergé par mes parents."

$8 \mathrm{Au}$ moment où les Italiens représentent près de $30 \%$ de la population étrangère de l'époque, la famille retrouve un coin d'Italie à Saint-Étienne :

“Nous n'habitions pas très loin de la Mission italienne, où ma mère allait à la messe et retrouvait ses cousines, ses amies et d'autres femmes d'immigrés de la Vallarsa. Il y avait aussi le Patronage Saint-Joseph, dirigé par les religieux de Saint-Vincent-dePaul, que mes frères fréquentaient. À 12 ans, Elvio est d'ailleurs entré au petit séminaire de cette congrégation. Ma mère en a été très fière ${ }^{6}$. Comme tous les immigrés, mes parents ont aussi envoyé de l'argent régulièrement à mes grandsparents paternels pour les aider. Et à la naissance de mon frère Maurice, Elvio est allé chez mes grands-parents paternels où il est resté quelque temps. Mais contrairement aux familles des frères de ma mère et des cousins de mon père, mes parents ne se rendaient pas tous les ans en Italie. Peut-être cela coûtait-il trop cher? Ce qui à la fois devait être dur, mais qui a sans doute favorisé leur intégration."

La famille s'agrandit de nouveau avec l'arrivée de Louis (10 juillet 1937), puis de MarieLouise (3 avril 1944). Mais, par crainte d'être renvoyé en Italie, et aussi en raison d'une certaine xénophobie à l'encontre des Italiens, Ettore demande sa naturalisation durant la Seconde Guerre mondiale. Il l'obtient pour toute la famille en juillet 1947, moment où 
Ettore et Giuseppina acquièrent leur première carte d'identité française. Giuseppina devient alors Joséphine et Ettore, Hector :

"Elvio et Maurice, ont été scolarisés à l'école primaire publique du quartier, où il y avait d'autres enfants d'immigrés de diverses nationalités. Louis et moi avons eu un régime différent. Nous avons été scolarisés dans des écoles privées. Pour ma part, contrairement à mes frères aînés, je n'ai jamais eu à souffrir de ma situation de petite fille d'immigrés. J'avais 3 ans lors de la naturalisation de mes parents sur laquelle je suis mentionnée. Mes frères l'ont été séparément."

\section{Le métier de plâtrier peintre, et les liens familiaux avec I'Italie}

Bien que sans qualification initiale, Ettore travaille dans le bâtiment tout au long de sa vie professionnelle. Maçon - par nécessité - à son arrivée, il devient par la suite plâtrier peintre. Ettore restera en fait chez son premier employeur jusqu'à ce que son fils, Maurice, plâtrier peintre lui aussi, monte sa propre entreprise en 1955. De même, après des études à l'école d'EDF, Louis travaillera lui aussi avec Maurice, avant d'avoir sa propre entreprise. Aujourd'hui, François, fils aîné de Louis, a repris le flambeau familial : il est à son tour artisan plâtrier peintre.

11 Parallèlement, Marie-Louise, qui deviendra assistante sociale, renoue avec les racines italiennes de la famille :

"J'avais 5 ans lorsque je suis allée en Italie pour la première fois avec ma mère et mes frères, pendant que mon père était resté à Saint-Étienne pour travailler. J'y ai connu mes grands-parents paternels à Camposilvano, la famille de la sœur de ma mère dans la banlieue de Vérone et celle des sœurs de mon père à Rovereto. J'y suis retournée en 1956 après le décès de mes grands-parents, lorsque mon père et son frère ont vendu la maison de Camposilvano. C'est après le décès de mon père que j'y suis retournée plus souvent, à partir du moment où mes frères ont eu une voiture. J'ai gardé des liens avec mes cousins et cousines. Récemment avec ma cousine Lina, fille de Virgilio, nous avons fait un pèlerinage à Camposilvano, où nous avons encore un cousin."

12 Mais les liens avec l'Italie ne concernent plus désormais que le seul passé : "Avec mon mari, André, nous avons deux filles. Anne, établie à Montluçon, et Laure, qui vit à Modène en Italie. Au cours de son année Erasmus à Milan, Laure a rencontré son mari, Luca Saracino, avec qui elle a eu deux enfants, Nils et Allegra. Aujourd'hui, nous allons souvent en Italie, puisque notre fille y réside et que sa belle famille est italienne." Le 5 décembre 2008, les deux cartes de Joséphine et d'Hector Pozzera, proposées par Marie-Louise et Louis, ont été soumises à la commission d'acquisition du musée. C'est ainsi que, depuis cette date, l'histoire de la famille Pozzera suggérée par ces papiers d'identité (voir photographie page 117) est venue s'insérer dans le patrimoine national. 


\section{NOTES}

1. "Lors d'un voyage, j'ai fait la connaissance d'un cousin de mon père qui avait fait des recherches généalogiques remontant simplement à la troisième génération mais qui m'a fait découvrir que mon trisaïeul, venait d'un village portant le nom de 'Contra Pozzera,' qui existe toujours" Marie-Louise Savoy.

2. Dans le périple vers Bevilaqua, Giuseppina perd sa mère, Virginia Martini, le 3 août 1916.

3. Ettore est l'aîné d'une famille de quatre enfants : Virgillio, Rosina et Marina.

4. Le 30 septembre 1919, l'Italie conclue un accord avec la France. Le gouvernement transalpin s'engage à fournir la main d'œuvre nécessaire contre l'engagement du gouvernement français à fournir aux recrues italiennes un traitement égal à celui des travailleurs français. Toutefois, l'État français abandonne bientôt cette gestion au secteur privé.

5. Voir Barjot, Dominique, "Les Italiens et le BTP français du début des années 1860 à la fin des années 1960 : ouvriers et patrons, une contribution multiforme", in L'Émigration-immigration italienne et les métiers du bâtiment en France et en Normandie, cahier des Annales de Normandie, $\mathrm{n}^{\circ} 3$, vol. I pp : 69-80.

6. Elvio deviendra prêtre des religieux de Saint-Vincent-de-Paul.

\section{RÉSUMÉS}

“Depuis toujours, j'ai été intéressée par tout ce qui touche à mes racines. Lorsque j'ai pris connaissance de l'ouverture d'un musée dédié à l'histoire de l'immigration, je me suis rendue sur son site Internet. Il m'a donné envie de visiter ce musée lors d'une visite à Paris. Ce voyage s'est déroulé début octobre 2008. Avant de partir, je suis retournée sur le site et j'ai poussé virtuellement - la porte de la galerie des dons. Cela m'a convaincue de participer à cette mémoire. D'apporter ce témoignage, peut-être inconsciemment pour mes petits-enfants, Amaury, Maëlys, Nils et Allegra, mais aussi pour rendre hommage à mes parents." Marie-Louise Savoy, fille d'Ettore et Giuseppina Pozzera.

\section{AUTEUR}

\section{FABRICE GROGNET}

Ethnologue, chargé de mission au Musée national de l'histoire et des cultures de l'immigration 